\title{
Few Drugs Display Flip-Flop Pharmacokinetics and These Are Primarily Associated with Classes 3 and 4 of the BDDCS
}

\author{
KIMBERLY L. GARRISON, ${ }^{1}$ SELMA SAHIN, ${ }^{1,2}$ LESLIE Z. BENET $^{1}$ \\ ${ }^{1}$ Department of Bioengineering and Therapeutic Sciences, University of California, San Francisco, San Francisco, California \\ ${ }^{2}$ Faculty of Pharmacy, Hacettepe University, Ankara, Turkey
}

Received 13 March 2015; revised 27 April 2015; accepted 28 April 2015

Published online 25 May 2015 in Wiley Online Library (wileyonlinelibrary.com). DOI 10.1002/jps.24505

\begin{abstract}
This study was conducted to determine the number of drugs exhibiting flip-flop pharmacokinetics following oral (p.o.) dosing from immediate-release dosage forms and if they exhibit a common characteristic that may be predicted based on BDDCS classification. The literature was searched for drugs displaying flip-flop kinetics (i.e., absorption half-life larger than elimination half-life) in mammals in PubMed, via internet search engines and reviewing drug pharmacokinetic data. Twenty two drugs were identified as displaying flip-flop kinetics in humans (13 drugs), rat (nine drugs), monkey (three drugs), horse (two drugs), and/or rabbit (two drugs). Nineteen of the 22 drugs exhibiting flip-flop kinetics were BDDCS Classes 3 and 4. One of the three exceptions, meclofenamic acid (Class 2), was identified in the horse; however, it would not exhibit flip-flop kinetics in humans where the p.o. dosing terminal half-life is $1.4 \mathrm{~h}$. The second, carvedilol, can be explained based on solubility issues, but the third sapropterin dihydrochloride (nominally Class 1 ) requires further consideration. The few drugs displaying p.o. flip-flop kinetics in humans are predominantly BDDCS Classes 3 and 4. New molecular entities predicted to be BDDCS Classes 3 and 4 could be liable to exhibit flip-flop kinetics when the elimination half life is short and should be suspected to be substrates for intestinal transporters. (c) 2015 Wiley Periodicals, Inc. and the American Pharmacists Association J Pharm Sci 104:3229-3235, 2015
\end{abstract}

Keywords: BDDCS; flip-flop pharmacokinetics; half-life; oral drug absorption; transporters; absorption; pharmacokinetics; intestinal absorption; disposition

\section{INTRODUCTION}

Accurate prediction of in vivo pharmacokinetics from in vitro measurements is an ongoing goal in the field of pharmaceutical sciences, and was a primary incentive in the establishment by Amidon et al. ${ }^{1}$ of the Biopharmaceutics Classification System (BCS). Wu and Benet ${ }^{2}$ built upon the BCS by modifying it to include information concerning drug elimination, and thus created the Biopharmaceutics Drug Disposition Classification System (BDDCS; Figure 1) to aid in predicting in vivo drug disposition by identifying the role of drug transporters, here presented with respect to effects in the intestine, as reviewed by Shugarts and Benet. ${ }^{3}$ The BDDCS gives scientists and clinicians a tool for predicting drug disposition and drug-drug interaction characteristics very early in the development and with little additional expense. This paper is dedicated to Professor Amidon in recognition of his outstanding and seminal contributions to the pharmaceutical sciences. It would not have been possible to conceive the BDDCS, ${ }^{2}$ without his prefatory insightful development of BCS. ${ }^{1}$

Gastrointestinal absorption is generally faster than elimination for most immediate-release, orally dosed drugs. However, there are exceptions characterized as flip-flop pharmacokinetics, in which the rate of absorption of a drug is slower than its rate of elimination. It is termed "flip-flop" because the absorp-

Abbreviations used: BCS, Biopharmaceutics Classification System; BDDCS, Biopharmaceutics Drug Disposition Classification System; i.v., intravenous; p.o., per os (oral).

Correspondence to: Leslie Z. Benet (Telephone: +415-476-3853; Fax: +415476-8887; E-mail: Leslie.Benet@ucsf.edu)

Kimberly L. Garrison's present address is Gilead Sciences, Inc., Foster City, California.

Journal of Pharmaceutical Sciences, Vol. 104, 3229-3235 (2015)

(C) 2015 Wiley Periodicals, Inc. and the American Pharmacists Association tion is the limiting process for elimination and a drug cannot be cleared from the system any faster than it enters into that system. It follows that observing an increased terminal elimination half-life following oral (p.o.) dosing of a drug, as compared with its intravenous (i.v.) half-life, is indicative of flip-flop pharmacokinetics, that is, although the ratio of a drug's absorption half-life to its elimination half-life $\left(t_{1 / 2, \text { abs }} / t_{1 / 2, \text { elim }}\right)$ is usually less than one, in the case of flip-flop kinetics, the ratio is greater than one. In 2011, Yáñez et al. ${ }^{4}$ published an extensive review of flip-flop pharmacokinetics, identifying 12 drugs exhibiting flipflop pharmacokinetics following immediate-release p.o. dosing.

It is hypothesized here that drugs exhibiting poor intestinal membrane permeability rate would be those most likely to display flip-flop kinetics, as also noted by Yáñez et al. ${ }^{4}$ Poorly permeable drugs generally have a low oil-to-water partition coefficient and are classified as BDDCS Classes 3 and 4, which are poorly metabolized. This report describes 19 drugs that display flip-flop kinetics and are poorly metabolized, although one of these poorly metabolized drugs displays a very weak flip-flop profile. These drugs are all associated with Classes 3 and 4 of the BDDCS. Based on these classifications, the BDDCS predicts that absorptive (uptake) transporters may play an important role in the gastrointestinal absorption of Classes 3 and 4 drugs (Figure 1). Here, we suggest that in vitro measures of permeability rate and extent of metabolism will predict whether a drug would be likely to display flip-flop kinetics in vivo.

\section{METHODS}

Drugs described in the literature as displaying flip-flop kinetics after p.o. dosing of immediate-release formulations in mammals (humans, monkeys, horses, rats, or rabbits) were 
High solubility

\begin{tabular}{|l|l|l|}
\hline \multicolumn{1}{|c|}{$\begin{array}{l}\text { CLASS 1 } \\
\text { Transporter effects }\end{array}$} & $\begin{array}{l}\text { CLASS 2 } \\
\text { Efflux transporter effects } \\
\text { predominate in gut }\end{array}$ \\
\hline $\begin{array}{l}\text { minimal in gut and } \\
\text { clinically negligible }\end{array}$ & \\
\hline & $\begin{array}{l}\text { CLASS 3 } \\
\text { Absorptive transporter } \\
\text { effects predominate in gut } \\
\text { (but can be modulated by } \\
\text { efflux transporters) }\end{array}$ & $\begin{array}{l}\text { Absorptive and efflux } \\
\text { transporter effects could } \\
\text { be important in gut }\end{array}$ \\
\hline &
\end{tabular}

Figure 1. The Biophamaceutics Drug Disposition Classification System predicts the effects of transporters on drug absorption in the gut.

identified in a survey of previously reported pharmacokinetic studies. Searches using the term "flip-flop [or flip flop] kinetics [and pharmacokinetics]" were performed in both PubMed and Web of Science, via various internet searches (e.g., Google) and reexaminations of specific drug categories as will be described. The search results were then gleaned to identify reports of flipflop drugs and their respective i.v. and p.o. half-lives. Studies investigating controlled-release formulations, prodrugs, or drugs administered via nonoral delivery sites (e.g., intramuscular, inhalation, etc.) were excluded from consideration. Close to 200 studies identifying flip-flop pharmacokinetics were found via the search processes utilized, with the overwhelming majority related to formulations developed to achieve flip-flop pharmacokinetics for drugs with short half-lives. For example, a recent publication ${ }^{5}$ reports flip-flop kinetics for the Class 1 drug mycophenolate in transplant patients for an enteric-coated formulation. Similarly, drugs with nonenzymatically catalyzed metabolism (e.g., thalidomide ${ }^{6}$ ) or drugs reported to display flip-flop kinetics under conditions of decreased intestinal motility that would affect absorption kinetics were also excluded (e.g., cephradine ${ }^{7}$ or dabigatran etexilate ${ }^{8,9}$ ). Two additional drugs were excluded because of the lack of corroborating evidence in the literature: a report of possible flip-flop kinetics of etoposide in children was ambiguous ${ }^{10}$; a single report of the i.v. half-life of vildagliptin in humans ${ }^{11}$ was within the range of p.o. half-lives reported in other human studies, ${ }^{12,13}$ and in addition, studies with vildagliptin in rats clearly demonstrated a lack of a flip-flop phenomenon. ${ }^{14}$

Where available, the reported terminal half-life after p.o. dosing of a drug was compared with the elimination half-life after i.v. dosing, and a ratio was calculated for each. Drugs were then classified into the BDDCS based on solubility and extent of metabolism following the tabulation of Benet et al. ${ }^{15} \mathrm{~A}$ drug is said to be highly soluble in both BCS and BDDCS when its highest dose strength is soluble in $250 \mathrm{~mL}$ or less of aqueous media over the $\mathrm{pH}$ range of $1-7.5$ at $37^{\circ} \mathrm{C} .{ }^{2}$ Drugs were classified as highly metabolized if metabolism accounts for at least $60 \%$ of its elimination..$^{15}$ Of the 22 drugs found to exhibit flipflop kinetics, 13 had a published BDDCS classification. ${ }^{15}$ The remaining nine were classified based on the above-mentioned criteria. Further searches of the literature were performed to identify which of these drugs were known substrates of the uptake and efflux transporters expressed on the intestinal lumen and liver.

\section{RESULTS}

Acamprosate, amoxicillin, ampicillin, calcium dosbesilate, carbovir, carvedilol, cefuroxime, cephalexin, fexofenadine, florfenicol, furosemide, levovirin, meclofenamic acid, metformin, nitrofurantoin, pravastatin, rebamipide, sapropterin, xamoterol, zanamivir, and zidovudine are reported to display flip-flop kinetics, whereas nedocromil is reported to show a weak trend toward flip-flop kinetics (Table 1). Each of these drugs, except for carvedilol, meclofenamic acid, and sapropterin, is eliminated primarily through excretion (i.e., poorly metabolized) and thus is assigned to Class 3 or 4 of the BDDCS. Interestingly, zidovudine displays flip-flop kinetics in rats, ${ }^{16}$ where it is poorly metabolized (20\%-30\% metabolized $)^{17-19}$ as compared with both monkeys $^{19,20}$ and humans ${ }^{19,21,22}$ in which zidovudine displays normal kinetics and is extensively metabolized $(60 \%-75 \%$ metabolized).

In the majority of cases presented in Table 1, the slow absorption process after an p.o. dose had a very obvious impact on pharmacokinetics and resulted in an observed terminal halflife that was longer by about twofold or greater as compared with the i.v. dose elimination half-life. One clear exception was nedocromil, for which the flip-flop trend was weak, and the absorption half-life to elimination half-life ratio was closer to one (Table 1). Notably, nedocromil has an inherently longer elimination half-life $(13.8 \mathrm{~h})$ than any of the other drugs $(0.3-7.7 \mathrm{~h})$ that displayed convincing flip-flop kinetics. Two BDDCS Class 2 drugs $^{30,37,38}$ and one Class 1 drug $^{45}$ are reported to exhibit flip-flop pharmacokinetics.

Classification into the BDDCS helps to predict whether uptake and/or efflux transporters in the gut will play a role in the absorption of a drug ${ }^{2,3}$ (Figure 1). The effects of transporters on the absorption of Class 1 compounds are negligible. For Class 2 compounds, the effects of efflux transporters are expected to dominate in the gut. The BDDCS predicts that absorptive transporter effects will predominate for Class 3 drugs, although efflux transporters in the gut may potentially modulate their disposition. For Class 4 drugs, the BDDCS predicts that the drug's disposition is likely to be affected by both absorptive and efflux transporters. Eighteen of the 21 drugs (omitting zidovudine) with flip-flop kinetics identified herein were poorly metabolized and thus classified as either Class 3 or 4 drugs. We recently reviewed intestinal drug transporters ${ }^{48}$ and only half of the drugs exhibiting flip-flop kinetics have been previously shown to be substrates for at least one uptake and/or efflux transporter (not limited to intestinal transporters) that may play an important role in their pharmacokinetics (Table 2). When the drug is listed as a substrate in the University of California, San Francisco-US Food and Drug Administration Transportal database ${ }^{49}$ this compilation provides primary reference sources.

\section{DISCUSSION}

There are currently two major drug classification systems in use, the BCS and the BDDCS, which are based on the 
Table 1. Drugs Displaying Flip-Flop Kinetics

\begin{tabular}{|c|c|c|c|c|c|}
\hline Drug & BDDCS Class & $t_{1 / 2, \text { i.v. }}(\mathrm{h})$ & $t_{1 / 2, \text { p.o. }}(\mathrm{h})$ & $t_{1 / 2, \text { p.o. }} / t_{1 / 2, \text { i.v. }}$ Ratio & Reference \\
\hline \multirow[t]{2}{*}{ Acamprosate } & 3 & 0.32 & 1.87 & 5.8 (rat) & 23,24 \\
\hline & & 3.2 & 32.7 & 10.2 (human) & \\
\hline Amoxicillin & 3 & 1.31 & 2.62 & 2.0 (human) & 25 \\
\hline Ampicillin & 3 & 0.78 & $2.35-3.24$ & $>3.0$ (human) & 26 \\
\hline Calcium dobesilate & 3 & 1.54 & 2.57 & 1.7 (human) & 27 \\
\hline Carbovir & 4 & 0.35 & 1.35 & 3.9 (rat) & 28,29 \\
\hline \multirow[t]{2}{*}{ Carvedilol } & 2 & 2.4 & 6.4 (capsule) & 2.7 (human) & 30 \\
\hline & & & 4.3 (suspension) & 1.8 (human) & \\
\hline Cefuroxime & 3 & 1.64 & 2.72 & 1.7 (rat) & 31 \\
\hline Cephalexin & 3 & 1.4 & Reported flip-flop & Reported flip-flop (rat) & 32 \\
\hline \multirow[t]{3}{*}{ Fexofenadine } & 3 & 2.4 & 5.0 & 2.1 (horse) & 33 \\
\hline & & 3.7 & 6.6 & $1.8($ monkey $)$ & \\
\hline & & Unknown & Varies & Reported flip-flop (human) & \\
\hline Florfenicol & 3 & 1.7 & 4.8 & 2.8 (rabbit) & 34 \\
\hline Furosemide & 4 & 2.8 & 4.9 & 1.8 (human) & 35 \\
\hline \multirow[t]{3}{*}{ Levovirin } & 3 & 3.5 & 12.2 & 3.5 (monkey) & 36 \\
\hline & & 1.5 & 4.5 & 3.0 (rat) & \\
\hline & & 3.7 & 4.1 & $1.1(\mathrm{dog})$ & \\
\hline Meclofenamic acid & 2 & 1.4 & 3.0 & 2.1 (horse) & 37,38 \\
\hline Metformin & 3 & 1.7 & 6.9 & 4.1 (human) & 39,40 \\
\hline Nedocromil & 3 & 13.8 & 15.9 & 1.2 (human) & 41 \\
\hline Nitrofurantoin & 4 & 0.25 & 0.63 & 2.5 (rabbit) & 42 \\
\hline Pravastatin & 3 & 0.78 & 1.77 & 2.3 (human) & 43 \\
\hline Rebamipide & 4 & 0.4 & 5.4 & 13.5 (rat) & 44 \\
\hline Sapropterin & 1 & 0.78 & 2.95 & 3.8 (human) & 45 \\
\hline Xamoterol & 3 & 7.7 & 16 & 2.1 (human) & 46 \\
\hline Zanamivir & 3 & 1.67 & 3.3 & 2.0 (human) & 47 \\
\hline \multirow[t]{3}{*}{ Zidovudine } & 3 & 1.6 & 3 to 4 & 2.2 (rat) & $16-22$ \\
\hline & 1 & 1.14 & 1.65 & 1.4 (monkey) & \\
\hline & & 1.1 & 1.0 & $<1$ (human) & \\
\hline
\end{tabular}

Table 2. Flip-Flop Drugs are Known Substrates for Transporters

\begin{tabular}{|c|c|c|c|}
\hline \multirow[b]{2}{*}{ Drug } & \multicolumn{2}{|c|}{ Gut and Liver Transporters } & \multirow[b]{2}{*}{ Reference } \\
\hline & Uptake & Efflux & \\
\hline Acamprosate & - & - & \\
\hline Amoxicillin & PEPT1 and PEPT2 & - & 49 \\
\hline Ampicillin & PEPT1 and PEPT2 & MRP4 & 50,51 \\
\hline Calcium dobesilate & - & - & \\
\hline Carbovir & Nucleoside and nucleobase & - & 52 \\
\hline Carvedilol & - & - & \\
\hline Cefuroxime & PEPT1 and PEPT2 & - & 50 \\
\hline Cephalexin & PEPT1 and OCTs & MATEs & 49 \\
\hline Fexofenadine & OATP1A2, OATP2B1, and OATP1B3 & BCRP, MDR1, MRP2, and MRP3 & 49 \\
\hline Florfenical & - & - & \\
\hline Furosemide & OAT3 & BCRP, MRP2, and MRP4 & $49,51,53,54$ \\
\hline Levovirin & - & - & \\
\hline Meclofenamic acid & - & - & \\
\hline Metformin & OCT1, OCT2, OCT3, and PMAT & MATE1 and MATE2K & 49,55 \\
\hline Nedocromil & - & - & \\
\hline Nitrofurantoin & - & & \\
\hline Pravastatin & MCT1, OATP1B1, OATP2B1, OAT3, and OAT4 & MRP2, MRP4, and MDR1 & $49,51,56-58$ \\
\hline Rebamipide & - & MRP4 & 51 \\
\hline Sapropterin & - & - & \\
\hline Xamoterol & - & - & \\
\hline Zanamivir & - & - & \\
\hline Zidovudine & CNT1, ENT2, OCTN2, OAT1, OAT2, OAT3, and OAT4 & BCRP, MDR1, MRP4, and MRP5 & $49,59-64$ \\
\hline
\end{tabular}

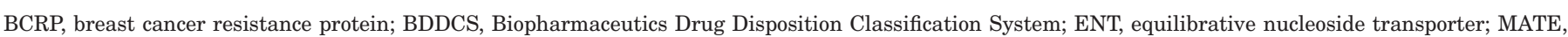

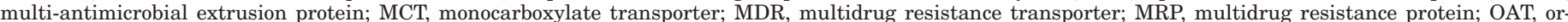

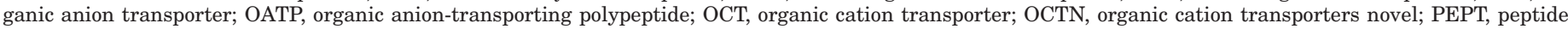
transporter; PMAT, plasma membrane monamine transporter. 
solubility and nominally the permeability of a drug. The BCS was developed to allow waiver of in vivo bioequivalence studies for highly soluble, highly permeable drugs, where rapid dissolution of immediate-release dosage forms could be established. ${ }^{1,65}$ However, as pointed out by Benet and Larregieu, ${ }^{66}$ the definitive criterion for assignment of Class $1 \mathrm{BCS}$ is $\geq 90 \%$ absorption, and, in fact, a number of poor permeability rate drugs relative to metoprolol (e.g., cefadroxil, cephradine, levofloxacin, loracarbef, ofloxacin, pregabalin, and sotalol) showing $\geq 90 \%$ absorption are assigned to BCS Class $1 .{ }^{67}$ In contrast, BDDCS was developed to predict drug disposition based on solubility and permeability rate, with the recognition that high permeability rate compounds were eliminated primarily by metabolism, whereas poor permeability rate drugs were eliminated by renal and biliary excretion of unchanged drug. ${ }^{2}$ A strength of the BDDCS for predicting disposition including drug absorption and flip-flop kinetics lies in the ability to easily obtain values for the extent of metabolism that are definitive, reliable, and generally consistent from study to study. Alternatively, we have recently shown that in vitro measurements of permeability rate predict BDDCS Classes 3 and 4 poor metabolism with $85.6 \pm 13.1 \%$ accuracy, which is better than utilizing in vitro permeability measurements to predict BDDCS Classes 1 and 2 extensive metabolism at $74 \pm 7 \% .{ }^{68}$ In the current report, all but three of the drugs found to display flip-flop kinetics were poorly metabolized and thus associated with Classes 3 and 4 of the BDDCS. Zidovudine is a particularly interesting example. It is classified as BDDCS Class 1 for its extensive metabolism in humans, in whom it lacks flip-flop kinetics; however, zidovudine is BDDCS Class 3 in rats in which it is poorly metabolized and displays flip-flop kinetics. ${ }^{16,22}$

One might expect that flip-flop kinetics would be observed with Class 2 drugs exhibiting poor solubility and/or extensive biliary recycling. However, neither we nor Yáñez et al. ${ }^{4}$ were able to identify any BDDCS Class 2 compound that exhibited flip-flop kinetics in humans except carvedilol. ${ }^{30}$ Here, in 20 healthy subjects, the carvedilol i.v. half-life was $2.4 \mathrm{~h}$, whereas the terminal half-life was $4.3 \mathrm{~h}$ for a $50 \mathrm{mg}$ suspension, and 7.1 and $6.4 \mathrm{~h}$ for a 25 and $50 \mathrm{mg}$ capsule, respectively. ${ }^{30} \mathrm{It}$ appears here that dissolution of this poorly soluble drug yielded the flip-flop kinetics for the suspension, with disintegration of the capsule (or dissolution of unwetted particles) causing a further increase in the terminal half-life. As noted in Table 1, an additional BDDCS Class 2 drug, meclofenamic acid, was found to exhibit flip-flop kinetics in horses. ${ }^{37,38}$ As with the great majority of the drugs in Table 1, meclofenamic acid exhibits a rapid i.v. half-life, $1.4 \mathrm{~h}$. Meclofenamic acid would not be expected to exhibit flip-flop kinetics in humans because the package insert indicates that following oral dosing in 10 subjects the mean elimination half-life was $1.3 \mathrm{~h}$, ranging from 0.8 to $2.1 \mathrm{~h}$.

As we had expected more Class 2 poorly soluble drugs to exhibit flip-flop pharmacokinetics, we examined 60 Class 2 drugs listed by Benet et al. ${ }^{15}$ with the highest dose numbers where p.o. and i.v. data are available without finding additional drugs to add to our list. We recognize that this is a very small subset of potential studies to examine. In the BDDCS classification, ${ }^{15}$ 230 Class 2 drugs are dosed orally, with each drug probably studied in two to four animal species and humans. Thus, approximately 500-900 studies could be investigated outside of those identified as exhibiting flip-flop pharmacokinetics. Similarly 188 Classes 3 and 4 orally dosed drugs may be found in the compilation. ${ }^{15}$ Of these 188 drugs, we were able to identify 113 compounds where bioavailability following p.o. and i.v. dosing was reported in the Goodman and Gilman Pharmacokinetic Data compilations (7th through 12th editions). One of these drugs, zanamivir, exhibited slower oral absorption than elimination that was not identified as flip-flop pharmacokinetics in the publication. ${ }^{47}$ We had previously identified zanamivir as exhibiting flip-flop pharmacokinetics following inhalation and intranasal administration, but did not identify the p.o. dosing data, and no p.o. dosage form of this drug had been approved (or submitted for approval), but we have included zanamivir in our listing in Table 1. Following identification of zanamivir, we carefully reviewed other drugs approved for inhalation or nasal administration. It is possible that albuterol may exhibit flip-flop pharmacokinetics following p.o. dosing, ${ }^{69}$ but our confidence in the report is not sufficient to list it here. We believe that the other two inhalation Classes 3 and 4 drugs listed in Benet et al., ${ }^{15}$, ipratropium and terbutaline, do not exhibit flipflop pharmacokinetics.

During the review process for this paper, flip-flop pharmacokinetics was reported for the drug sapropentin dihydrochloride in infants and young children with phenylketonuria. ${ }^{45}$ Sapropentin dihydrochloride is a synthetic preparation of the naturally occurring phenylalanine hydroxylase cofactor tetrahydrobiopterin (BH4). We have listed the drug as BDDCS Class 1 because it is dehydrated by the enzyme $\mathrm{PCD} / \mathrm{DCoH}$ (pterin-4a-carbinolamine dehydratase/dimerization cofactor of hepatocyte nuclear factor $1 \alpha) .{ }^{70}$ However, the body regenerates $\mathrm{BH} 4$ in vivo and the major route of elimination in humans is via the bile. Thus, in fact, because of the regeneration process, sapropentin dihydrochloride might be considered to have BDDCS Class 3 characteristics. However, as noted in Table 2, transporter effects on sapropentin (or BH4) have not been identified.

The current findings describe a further benefit of employing the BDDCS early in drug development. It is proposed that Classes 3 and 4 drugs are primarily susceptible to flip-flop kinetics in humans, and the data suggest that such disposition is likely to be most apparent and a more important consideration for drugs with relatively short half-lives. One would like to know whether a drug exhibits flip-flop pharmacokinetics so as to be able to define the rate-limiting step in drug elimination and to predict potential drug interactions and the potential liability for toxicity - lack of efficacy outcomes.

Given that transit through the small intestine takes only a few hours following gastric emptying, ${ }^{71}$ the presence of a flip-flop phenomenon for immediate-release drugs would intuitively only be possible for drugs with half-lives not exceeding their gastrointestinal transit time. Additionally, classification as BDDCS Class 3 or 4 has implications for both drug-drug interactions as well as pharmacogenetics. In the former case, concomitant administration of another drug that affects the expression or function of a given transporter or enzyme may alter the pharmacokinetics of the drug of interest and potentially result in drug concentrations in either subtherapeutic or toxic ranges. In the latter situation, the natural variation of transporter expression or function also has the potential to affect a drug's disposition. For example, polymorphisms in OCT1 affect the pharmacokinetics of metformin in humans. ${ }^{72}$ Thus, use of the BDDCS during early-stage development of novel drugs will help to identify those drugs that may encounter important transporter effects that require more directed characterization of their disposition. 
Although flip-flop pharmacokinetics is a topic found in almost all pharmacokinetics textbooks and a topic of presentation in courses taught both in academia and in short courses taught to industrial scientists, there are very few drugs that inherently exhibit slower p.o. absorption than elimination (vs. many controlled-release drug products designed to achieve this phenomenon). This was found by Yáñez et al. ${ }^{4}$ and reviewed here. In fact, of the 698 orally dosed drugs examined by Benet et al. ${ }^{15}$ only nine are here documented to exhibit flip-flop pharmacokinetics in humans.

In summary, this report demonstrates that poorly metabolized drugs in BDDCS Classes 3 and 4 are associated with flip-flop kinetics in cases where the drugs have relatively short half-lives. Furthermore, absorptive and efflux transporters may potentially play important roles in the disposition of BDDCS Classes 3 and 4 drugs. It might be expected that poorly soluble Class 2 drugs should also exhibit flip-flop kinetics where absorption is limited by dissolution, although only one example was identified. The implications of these findings are that simple in vitro measures of solubility and permeability rate can be used with the BDDCS early in development to predict whether flip-flop pharmacokinetics might occur (although few drugs would actually be expected to do so) and gut transporters are likely to influence the in vivo pharmacokinetic behavior of a new molecular entity. Thus, the BDDCS classification helps to identify compounds early on for which increased characterization of transporter interactions may be necessary for the purpose of predicting potential drug-drug interactions including transporter-enzyme interplay, as well as assessing the potential importance of pharmacogenetic variability in a population.

\section{ACKNOWLEDGMENT}

The work presented here was supported in part by NIH grants GM75900 and GM61390.

\section{REFERENCES}

1. Amidon GL, Lennernas H, Shah VP, Crison JR. 1995. A theoretical basis for a biopharmaceutic drug classification: The correlation of in vitro drug product dissolution and in vivo bioavailability. Pharm Res 12(3):413-420.

2. Wu CY, Benet LZ. 2005. Predicting drug disposition via application of BCS: Transport/absorption/elimination interplay and development of a biopharmaceutics drug disposition classification system. Pharm Res 22(1):11-23.

3. Shugarts S, Benet LZ. 2009. The role of transporters in the pharmacokinetics of orally administered drugs. Pharm Res 26(9):2039-2054.

4. Yáñez JA, Remsberg CM, Sayre CL, Forrest ML, Davies NM. 2011. Flip-flop pharmacokinetics-Delivering a reversal of disposition: Challenges and opportunities during drug development. Ther Deliv 2(5):643-672.

5. Han N, Yun HY, Kim IW, Oh YJ, Kim YS, Oh JM. 2014. Population pharmacogenetic pharmacokinetic modeling for flip-flop phenomenon of enteric-coated mycophenolate sodium in kidney transplant recipients. Eur J Clin Pharmacol 70(10):1211-1219.

6. Schumacher H, Smith RL, Williams RT. 1965. The metabolism of thalidomide: The spontaneous hydrolysis of thalidomide in solution. $\mathrm{Br}$ J Pharmacol Chemother 25(2):324-337.

7. Philipson A, Stiernstedt G, Ehrnebo M. 1987. Comparison of the pharmacokinetics of cephradine and cefazolin in pregnant and nonpregnant women. Clin Pharmacokinet 12(2):136-144.
8. Blech S, Ebner T, Ludwig-Schwellinger E, Stangier J, Roth W. 2008. The metabolism and disposition of the oral direct thrombin inhibitor, dabigatran, in humans. Drug Metab Dispos 36(2):386-399.

9. Troconiz IF, Tillmann C, Liesenfeld KH, Schafer HG, Stangier J. 2007. Population pharmacokinetic analysis of the new oral thrombin inhibitor dabigatran etexilate (BIBR 1048) in patients undergoing primary elective total hip replacement surgery. J Clin Pharmacol 47(3):371-382.

10. Edick MJ, Gajjar A, Mahmoud HH, van de Poll ME, Harrison PL, Panetta JC, Rivera GK, Ribeiro RC, Sandlund JT, Boyett JM, Pui CH, Relling MV. 2003. Pharmacokinetics and pharmacodynamics of oral etoposide in children with relapsed or refractory acute lymphoblastic leukemia. J Clin Oncol 21(7):1340-1346.

11. He YL, Sadler BM, Sabo R, Balez S, Wang Y, Campestrini J, Laurent A, Ligueros-Saylan M, Howard D. 2007. The absolute oral bioavailability and population-based pharmacokinetic modelling of a novel dipeptidylpeptidase-IV inhibitor, vildagliptin, in healthy volunteers. Clin Pharmacokinet 46(9):787-802.

12. He H, Tran P, Yin H, Smith H, Batard Y, Wang L, Einolf H, Gu H, Mangold JB, Fischer V, Howard D. 2009. Absorption, metabolism, and excretion of [14C]vildagliptin, a novel dipeptidyl peptidase 4 inhibitor, in humans. Drug Metab Dispos 37(3):536-544.

13. Hu P, Yin Q, Deckert F, Jiang J, Liu D, Kjems L, Dole WP, He YL. 2009. Pharmacokinetics and pharmacodynamics of vildagliptin in healthy Chinese volunteers. J Clin Pharmacol 49(1):39-49.

14. He H, Tran P, Yin H, Smith H, Flood D, Kramp R, Filipeck R, Fischer V, Howard D. 2009. Disposition of vildagliptin, a novel dipeptidyl peptidase 4 inhibitor, in rats and dogs. Drug Metab Dispos 37(3):545-554.

15. Benet LZ, Broccatelli F, Oprea TI. 2011. BDDCS applied to over 900 drugs. AAPS J 13(4):519-547.

16. Melvin GC, Ellison SR, Monk CM, Bates TR. 1990. Existence of a flip-flop kinetic model for zidovudine (AZT) after oral administration. Res Commun Chem Pathol Pharmacol 70(2):193-204.

17. Mays DC, Dixon KF, Balboa A, Pawluk LJ, Bauer MR, Nawoot S, Gerber N. 1991. A nonprimate animal model applicable to zidovudine pharmacokinetics in humans: Inhibition of glucuronidation and renal excretion of zidovudine by probenecid in rats. J Pharmacol Exp Ther 259(3):1261-1270.

18. Patel BA, Chu CK, Boudinot FD. 1989. Pharmacokinetics and saturable renal tubular secretion of zidovudine in rats. J Pharm Sci 78(7):530-534.

19. Good SS, Durack DT, de Miranda P. 1986. Biotransformation in various species and in humans of 3'-azido-3'-deoxythymidine, a potential agent for the treatment of AIDS. Fed Proc 45:444.

20. Qian MX, Finco TS, Mehta M, Viswanathan CT, Gallo JM. 1991. Pharmacokinetic evaluation of drug interactions with zidovudine. I: Probenecid and zidovudine in monkeys. J Pharm Sci 80(11):10071011.

21. Blum MR, Liao SH, Good SS, de Miranda P. 1988. Pharmacokinetics and bioavailability of zidovudine in humans. Am J Med 85(2A):189194.

22. Klecker RW Jr, Collins JM, Yarchoan R, Thomas R, Jenkins JF, Broder S, Myers CE. 1987. Plasma and cerebrospinal fluid pharmacokinetics of 3'-azido-3'-deoxythymidine: A novel pyrimidine analog with potential application for the treatment of patients with AIDS and related diseases. Clin Pharmacol Ther 41(4):407-412.

23. Saivin S, Hulot T, Chabac S, Potgieter A, Durbin P, Houin G. 1998. Clinical pharmacokinetics of acamprosate. Clin Pharmacokinet 35(5):331-345.

24. Zornoza T, Cano-Cebrián MJ, Hipólito L, Granero L, Polache A. 2006. Evidence of a flip-flop phenomenon in acamprosate pharmacokinetics: an in vivo study in rats. Biopharm Drug Dispos 27(7):305-311. 25. Paintaud G, Alván G, Dahl ML, Grahnén A, Sjövall J, Svensson JO. 1992. Nonlinearity of amoxicillin absorption kinetics in human. Eur $J$ Clin Pharmacol 43(3):283-288.

26. Tanigawara Y, Yamaoka K, Nakagawa T, Uno T. 1982. Moment analysis for the separation of mean in vivo disintegration, dissolution, 
absorption, and disposition time of ampicillin products. J Pharm Sci 71(10):1129-1133.

27. Franke G, Schneider T, Siegmund W, Scherber A. 1985. Bioavailability studies of calcium dobesilate-A case of flip-flop kinetics. Pharmazie 40(8):562-563.

28. Walsh JS, Patanella JE, Unger SE, Brouwer KR, Miwa GT. 1990. The metabolism and excretion of carbovir, a carbocyclic nucleoside, in the rat. Drug Metab Dispos 18(6):1084-1091.

29. Yeom YH, Remmel RP, Huang SH, Hua M, Vince R, Zimmerman CL. 1989. Pharmacokinetics and bioavailability of carbovir, a carbocyclic nucleoside active against human immunodeficiency virus, in rats. Antimicrob Agents Chemother 33(2):171-175.

30. von Möllendorff E, Reiff K, Neugebauer G. 1987. Pharmacokinetics and bioavailability of carvedilol, a vasodilating beta-blocker. Eur J Clin Pharmacol 33(5):511-513.

31. Ruiz-Carretero P, Nacher A, Merino-Sanjuan M, Casabo VG. 2000. Pharmacokinetics and absolute bioavailability of oral cefuroxime axetil in the rat. Int J Pharm 202(1-2):89-96.

32. Padoin C, Tod M, Perret G, Petitjean O. 1998. Analysis of the pharmacokinetic interaction between cephalexin and quinapril by a nonlinear mixed-effect model. Antimicrob Agents Chemother 42(6):14631469.

33. Chen C. 2007. Some pharmacokinetic aspects of the lipophilic terfenadine and zwitterionic fexofenadine in humans. Drugs R D 8(5):301314.

34. Abd El-Aty AM, Goudah A, Abo El-Sooud K, El-Zorba HY, Shimoda M, Zhou HH. 2004. Pharmacokinetics and bioavailability of florfenicol following intravenous, intramuscular and oral administrations in rabbits. Vet Res Commun 28(6):515-524.

35. Fredrick MJ, Pound DC, Hall SD, Brater DC. 1991. Furosemide absorption in patients with cirrhosis. Clin Pharmacol Ther 49(3):241247.

36. Lin CC, Luu T, Lourenco D, Yeh LT, Lau JY. 2003. Absorption, pharmacokinetics and excretion of levovirin in rats, dogs and cynomolgus monkeys. J Antimicrob Chemother 51(1):93-99.

37. Johansson IM, Kallings P, Hammarlund-Udenaes M. 1991. Studies of meclofenamic acid and two metabolites in horses-Pharmacokinetics and effects on exercise tolerance. J Vet Pharmacol Ther 14(3):235-242. 38. Snow DH, Baxter P, Whiting B. 1981. The pharmacokinetics of meclofenamic acid in the horse. J Vet Pharmacol Ther 4(2):147-156.

39. Pentikäinen PJ, Neuvonen PJ, Penttilä A. 1979. Pharmacokinetics of metformin after intravenous and oral administration to man. Eur J Clin Pharmacol 16(3):195-202.

40. Sambol NC, Chiang J, Lin ET, Goodman AM, Liu CY, Benet LZ, Cogan MG. 1995. Kidney function and age are both predictors of pharmacokinetics of metformin. J Clin Pharmacol 35(11):1094-1102.

41. Neale MG, Brown K, Foulds RA, Lal S, Morris DA, Thomas D. 1987. The pharmacokinetics of nedocromil sodium, a new drug for the treatment of reversible obstructive airways disease, in human volunteers and patients with reversible obstructive airways disease. $\mathrm{Br} \mathrm{J}$ Clin Pharmacol 24(4):493-501.

42. Watari N, Funaki T, Aizawa K, Kaneniwa N. 1984. A flip-flop model for nitrofurantoin disposition in the rabbit following oral administration. Int J Pharm 21(1):85-98.

43. Singhvi SM, Pan HY, Morrison RA, Willard DA. 1990. Disposition of pravastatin sodium, a tissue-selective HMG-CoA reductase inhibitor, in healthy subjects. Br J Clin Pharmacol 29(2):239-243.

44. Shin BS, Kim CH, Jun YS, Yoon CH, Rho JI, Lee KC, Han HS, Yoo SD. 2004. Oral absorption and pharmacokinetics of rebamipide and rebamipide lysinate in rats. Drug Dev Ind Pharm 30(8):869-876.

45. Qi Y, Mould DR, Zhou H, Merilainen M, Musson DG. 2015. A prospective population pharmacokinetic analysis of sapropterin dihydrochloride in infants and young children with phenylketonuria. Clin Pharmacokinet 54(2):195-207.

46. Bastain W, Boyce MJ, Stafford LE, Morton PB, Clarke DA, Marlow HF. 1988. Pharmacokinetics of xamoterol after intravenous and oral administration to volunteers. Eur J Clin Pharmacol 34(5):469473.
47. Cass LM, Efthymiopoulos C, Bye A. 1999. Pharmacokinetics of zanamivir after intravenous, oral, inhaled or intranasal administration to healthy volunteers. Clin Pharmacokinet 36(Suppl 1):111.

48. Estudante M, Morais JG, Soveral G, Benet LZ. 2013. Intestinal drug transporters: an overview. Adv Drug Deliv Rev 65(10):1340 1356 .

49. Morrissey KM, Wen CC, Johns SJ, Zhang L, Huang SM, Giacomini KM. 2012. The UCSF-FDA TransPortal: A public drug transporter database. Clin Pharmacol Ther 92(5):545-546.

50. Luckner P, Brandsch M. 2005. Interaction of 31 beta-lactam antibiotics with the $\mathrm{H}+$ /peptide symporter PEPT2: Analysis of affinity constants and comparison with PEPT1. Eur J Pharm Biopharm 59(1):1724.

51. Uchida Y, Kamiie J, Ohtsuki S, Terasaki T. 2007. Multichannel liquid chromatography-tandem mass spectrometry cocktail method for comprehensive substrate characterization of multidrug resistance-associated protein 4 transporter. Pharm Res 24(12):22812296.

52. Mahony WB, Domin BA, Daluge SM, Zimmerman TP. 2004. Membrane permeation characteristics of abacavir in human erythrocytes and human T-lymphoblastoid CD4 + CEM cells: Comparison with (-)carbovir. Biochem Pharmacol 68(9):1797-1805.

53. Bakos E, Evers R, Sinkó E, Váradi A, Borst P, Sarkadi B. 2000. Interactions of the human multidrug resistance proteins MRP1 and MRP2 with organic anions. Mol Pharmacol 57(4):760-768.

54. Hasegawa M, Kusuhara H, Adachi M, Schuetz JD, Takeuchi K, Sugiyama Y. 2007. Multidrug resistance-associated protein 4 is involved in the urinary excretion of hydrochlorothiazide and furosemide. J Am Soc Nephrol 18(1):37-45.

55. Zhou M, Xia L, Wang J. 2007. Metformin transport by a newly cloned proton-stimulated organic cation transporter (plasma membrane monoamine transporter) expressed in human intestine. Drug Metab Dispos 35(10):1956-1962.

56. Tamai I, Takanaga H, Maeda H, Sai Y, Ogihara T, Higashida H, Tsuji A. 1995. Participation of a proton-cotransporter, MCT1, in the intestinal transport of monocarboxylic acids. Biochem Biophys Res Commun 214(2):482-489.

57. Tokui T, Nakai D, Nakagomi R, Yawo H, Abe T, Sugiyama Y. 1999. Pravastatin, an HMG-CoA reductase inhibitor, is transported by rat organic anion transporting polypeptide, oatp2. Pharm Res 16(6):904908.

58. Yamazaki M, Akiyama S, Ni’inuma K, Nishigaki R, Sugiyama Y. 1997. Biliary excretion of pravastatin in rats: Contribution of the excretion pathway mediated by canalicular multispecific organic anion transporter. Drug Metab Dispos 25(10):1123-1129.

59. Abla N, Chinn LW, Nakamura T, Liu L, Huang CC, Johns SJ, Kawamoto M, Stryke D, Taylor TR, Ferrin TE, Giacomini KM, Kroetz DL. 2008. The human multidrug resistance protein 4 (MRP4, ABCC4): Functional analysis of a highly polymorphic gene. J Pharmacol Exp Ther 325(3):859-868.

60. Georges B, Galland S, Rigault C, Le Borgne F, Demarquoy J. 2003. Beneficial effects of L-carnitine in myoblastic C2C12 cells. Interaction with zidovudine. Biochem Pharmacol 65(9):1483-1488.

61. Jorajuria S, Dereuddre-Bosquet N, Becher F, Martin S, Porcheray F, Garrigues A, Mabondzo A, Benech H, Grassi J, Orlowski S, Dormont D, Clayette P. 2004. ATP binding cassette multidrug transporters limit the anti-HIV activity of zidovudine and indinavir in infected human macrophages. Antivir Ther 9(4):519-528.

62. Pan G, Giri N, Elmquist WF. 2007. Abcg2/Bcrp1 mediates the polarized transport of antiretroviral nucleosides abacavir and zidovudine. Drug Metab Dispos 35(7):1165-1173.

63. Ritzel MW, Yao SY, Huang MY, Elliott JF, Cass CE, Young JD. 1997. Molecular cloning and functional expression of cDNAs encoding a human $\mathrm{Na}^{+}$-nucleoside cotransporter (hCNT1). Am J Physiol 272(2 Pt 1):C707-C714.

64. Yao SY, Ng AM, Sundaram M, Cass CE, Baldwin SA, Young JD. 2001. Transport of antiviral 3'-deoxy-nucleoside drugs by recombinant 
human and rat equilibrative, nitrobenzylthioinosine (NBMPR)insensitive (ENT2) nucleoside transporter proteins produced in Xenopus oocytes. Mol Membr Biol 18(2):161-167.

65. Food and Drug Administration. 2000. Guidance for industry: Waiver of in vivo bioavailability and bioequivalence studies for immediate release solid oral dosage forms based on a Biopharmaceutics Classification System. www.fda.gov/cder/guidance/index.htm, part of U.S. Food and Drug Administration Center for Drug Evaluation and Research. http://www.fda.gov/Cder/.

66. Benet LZ, Larregieu CA. 2010. The FDA should eliminate the ambiguities in the current BCS biowaiver guidance and make public the drugs for which BCS biowaivers have been granted. Clin Pharmacol Ther 88(3):405-407.

67. Chen M, Yu L. 2009. The use of drug metabolism for prediction of intestinal permeability. Mol Pharm 6(1):74-81.
68. Hosey CM, Benet LZ. 2015. Predicting the extent of metabolism using in vitro permeability rate measurements and in silico permeability rate predictions. Mol Pharm 12(5):1456-1466.

69. Boulton DW, Fawcett JP. 1996. Enantioselective disposition of salbutamol in man following oral and intravenous administration. Br J Clin Pharmacol 41(1):35-40.

70. Thony B, Auerbach G, Blau N. 2000. Tetrahydrobiopterin biosynthesis, regeneration and functions. Biochem J 347(Pt 1):1-16.

71. Benmair Y, Fischel B, Frei EH, Gilat T. 1977. Evaluation of a magnetic method for the measurement of small intestinal transit time. Am J Gastroenterol 68(5):470-475.

72. Shu Y, Brown C, Castro RA, Shi RJ, Lin ET, Owen RP, Sheardown SA, Yue L, Burchard EG, Brett CM, Giacomini KM. 2008. Effect of genetic variation in the organic cation transporter 1, OCT1, on metformin pharmacokinetics. Clin Pharmacol Ther 83(2):273-280. 